Check for updates

The BMJ

Cite this as: BMJ2020;370:m2825 http://dx.doi.org/10.1136/bmj.m2825 Published: 14 July 2020

\section{Covid-19: UK must prepare now for winter peak or risk many more deaths, scientists warn}

Gareth lacobucci

The UK must prepare now for a potential second wave of covid-19 this winter or risk seeing double the number of hospital deaths that occurred during the first wave, the Academy of Medical Sciences has warned.

In a report ${ }^{1}$ it said that the combination of covid-19, a backlog of patients needing NHS assessment and treatment, and the possibility of a flu epidemic posed "a serious risk" to health in the UK.

The academy called for "intense preparation" throughout the rest of July and August to reduce the risk of the NHS being overwhelmed and to save lives this winter.

Central to this should be minimising transmission of covid-19 in the community, and increasing capacity of the national test, trace, and isolate programme to cope with the overlapping symptoms of covid-19, flu, and other winter infections, it said.

Health and care staff and facilities should be reorganised to maintain covid-19 and covid-19-free zones, and there must be adequate personal protective equipment, testing, and infection control measures to minimise transmission in hospitals and care homes, it said.

There should also be a "concerted effort" to make sure at-risk people and health and care workers get flu vaccinations, it added.

Anne Johnson, a member of the expert group for the project and the Academy of Medical Sciences' vice president (international), said, "We need to minimise coronavirus and flu transmission everywhere, especially in hospitals and care homes. This can be done, but it must be done now.”

The report acknowledges the high degree of uncertainty about how the covid-19 epidemic will evolve in the UK but suggested that a "reasonable worst case scenario" to prepare for is the R value rising to 1.7 from September 2020 onwards.

Under this scenario, there would be a peak in hospital admissions and deaths in January and February 2021 similar to or worse than the first wave in spring 2020, it said.

This modelling estimates the number of covid-19-related hospital deaths (excluding care homes) between September 2020 and June 2021 could be as high as 119900 (95\% confidence interval 24500 to 251 ooo), over double the number that occurred during the first wave in spring 2020.

But the report noted that these estimated figures do not take account of government actions to reduce transmission rate, or recent results from a trial to treat patients in intensive care with the steroid dexamethasone, ${ }^{2}$ which could substantially reduce mortality.

Stephen Holgate, a respiratory specialist from University Hospital Southampton NHS Foundation Trust, who chaired the report, said, "This is not a prediction, but it is a possibility. The modelling suggests that deaths could be higher with a new wave of covid-19 this winter, but the risk of this happening could be reduced if we take action immediately.

"With relatively low numbers of covid-19 cases at the moment, this is a critical window of opportunity to help us prepare for the worst that winter can throw at us."

The report was produced following a request by the government's chief scientific advisor by an advisory group of 37 experts.

Academy of Medical Sciences. Preparing for a challenging winter 2020-21. 14 July 2020. https://acmedsci.ac.uk.

Mahase E. Covid-19: Low dose steroid cuts death in ventilated patients by one third, trial finds. BMJ2020;369:m2422. doi: 10.1136/bmj.m2422 pmid: 32546467

This article is made freely available for use in accordance with BMJ's website terms and conditions for the duration of the covid-19 pandemic or until otherwise determined by BMJ. You may use, download and print the article for any lawful, non-commercial purpose (including text and data mining) provided that all copyright notices and trade marks are retained. 